\title{
Studies on Antinephritic Effect of TJ-8014, a New Japanese Herbal Medicine (3): Effects on Crescentic-Type Anti-GBM Nephritis in Rats
}

\author{
Tomohisa HATTORI, Mikio ITO, Tadashi NAGAMATSU \\ and Yoshio SUZUKI \\ Department of Pharmacology. Faculty of Pharmacy. Meijo University, \\ Tenpaku-ku, Nagoya 468, Japan \\ Accepted September 30, 1989
}

\begin{abstract}
We investigated the antinephritic effects of $\mathrm{TJ}-8014$, in comparison to dipyridamole. on crescentic-type anti-GBM nephritis in rats. When administration of test drugs was started from the heterologous phase (from the day after the anti-GBM serum injection). TJ -8014 at $2.0 \mathrm{~g} / \mathrm{kg} /$ day, p.o., markedly inhibited the urinary protein excretion and elevations of plasma cholesterol and urea nitrogen levels as well as glomerular histopathological changes (i.e., crescent formation, adhesion and fibrinoid necrosis) throughout the 40-day observation period. TJ 8014 at 0.1 and $0.5 \mathrm{~g} / \mathrm{kg} /$ day, p.o., and dipyridamole at $0.4 \mathrm{~g} /$ day, p.o., inhibited only the histopathological changes. When treatment was started from the autologous phase (from the 22nd day after the anti-GBM serum injection) after the disease had been established, only the high dose of $5.0 \mathrm{~g} / \mathrm{kg} /$ day of TJ-8014, p.o., was effective in improving the histopathological changes of the established nephritis, as assessed on the 53rd day. The low doses of TJ -8014 and dipyridamole were ineffective. These results suggest that $T J-8014$ may be a useful Japanese herbal medicine against rapidly progressive glomerulonephritis. which is characterized by severe glomerular lesions with the extensive formation of crescents. Furthermore, the mechanisms of action of this medicine will be discussed.
\end{abstract}

Recently, in Japan, there has been a rapid increase in the use of Japanese herbal medicines containing Bupleuri Root (Bupleuri radix) mainly for the therapy of nephritis or nephrotic syndrome. On the other hand, it has been demonstrated by us $(1,2)$ and Abe et al. (3) that two Japanese herbal medicines con- taining Bupleuri Root, Chai-Ling-Tang (Sairei-to in Japanese) and Xiao-Chai-HuTang (Syo-saiko-to in Japanese) are effective on nephritis or nephrosis in experimental animal models.

TJ-8014 is a lyophilized extract prepared from eight crude drugs containing Bupleuri

Table 1. Compositions of crude drugs that constitute TJ-8014

\begin{tabular}{|c|c|c|}
\hline Crude drugs & & Contents $^{1}(\mathrm{~g})$ \\
\hline Bupleuri radix & (SAIKO) & 7 \\
\hline Pinelliae tuber & (HANGE) & 5 \\
\hline Glyoyrrhizae radix & (KANZOU) & 2 \\
\hline Scutellariae radix & (OUGON) & 3 \\
\hline Ginseng radix & $(N \mid N J I N)$ & 3 \\
\hline Coptidis rhizoma & (OUREN) & 1 \\
\hline Holen & (BUKURYOU) & 3 \\
\hline Zizyphi fructus & (TAISOU) & 3 \\
\hline
\end{tabular}

1 The amounts of each crude drug required to prepare $4.5 \mathrm{~g}$ of $\mathrm{TJ}-8014$ extract. 
Root as shown in Table 1, which is now being developed by Tsumura Co, Ltd. as a new antinephritic agent. We have already reported that $T J-8014$ is markedly effective in reducing proteinuria and preventing glomerular histopathological changes in original-type antiglomerular basement membrane (anti-GBM) nephritis induced in rats by a single i.v. in jection of rabbit anti-GBM! serum (4)

This model is characterized by moderate proteinuria and mild proliferation of mesangial cells, and it resembles mild proliferative glomerulonephritis in humans (5). Human glomerulonephritis is classified into various types on the bases of clinical and histopathological findings. We previously established a model of crescentic-type glomerulonephritis closely resembling rapidly progressive glomerulonephritis in humans, which was characterized by severe glomerular lesions with extensive formation of crescents, by immunizing with rabbit $r$-globulin following i.v. injection of rabbit anti-GBM serum into rats (6)

The present study was designed to clarify the antinephritic effect of TJ-8014 on crescentic-type anti-GBM nephritis in rats in comparison with that of dipyridamole, an antiplatelet agent, which had been proven to be effective in this model (7).

\section{Materials and Methods}

Animals: Male Sprague-Dawley strain SPF rats (Nihon SLC, Shizuoka), weighing approx. $155 \mathrm{~g}$, were used in the experiment. These animals were housed in an air-conditioned room at $23 \pm 1^{\circ} \mathrm{C}$ during the experimental periods.

Drugs: Drugs used were TJ-8014 (a lyophilized extract. Tsumura Co. Ltd., Tokyo) and dipyridamole (Boehringer Ingeiheim. West Germany). These drugs were suspended in $1 \%$ gum arabic.

Induction of crescentic-type anti-GBM nephritis: Crescentic-type anti-GBM nephritis was induced in rats by injecting $6.5 \mathrm{mg}$ rabbit $\gamma$-globulin $(\gamma-G)$ in $0.25 \mathrm{ml}$ of Freund's complete adjuvant (FCA) into their hind foot pads, following i.v. injection of $1.0 \mathrm{ml}$ of rabbit antirat GBM serum into the tail vein in accordance with the method reported previously (6).

in this experiment, the effects of test drugs were examined by administering them from the heterologous (from the day after the antiGBM serum injection) and autologous (the 22nd day after the anti-GBM serum injection) phases. In the experiment in which the drug was administered from the heterologous phase, immediately after the anti-GBM serum injection, $24 \mathrm{hr}$ urine samples were collected The animals were then divided into 5 groups $(n=8)$. so that the average protein content in the 24 hr urine samples of each group was at the same level. After grouping, these animals were immunized with rabbit $\gamma-G$ in FCA. Four groups were given 0.1 .0 .5 and $2.0 \mathrm{~g} / \mathrm{kg}$ of TJ 8014 and $0.4 \mathrm{~g} / \mathrm{kg}$ of dipyridamole, respectively, in a volume of $1 \mathrm{ml}$ per $100 \mathrm{~g}$ of body weight, orally, daily from the day after the antiGBM serum injection (the 1st day) to the 39 th day. The remaining group was orally given the vehicle ( $1 \%$ gum arabic) instead of test drugs and served as the control. In addition, a non-treated (normal) group $(n=8)$ was used for comparison with the nephritic group.

In the experiment in which the drug was administered from the autologous phase. the nephritic rats were divided into 4 groups $(n=8)$. Three groups were given 2.0 and 5.0 $\mathrm{g} / \mathrm{kg}$ of $\mathrm{TJ}-8014$ and $0.4 \mathrm{~g} / \mathrm{kg}$ of dipyridamole, respectively, orally, daily from the $22 \mathrm{nd}$ day to the 53 rd day. The remaining group was given only the vehicle as the control. In addition, a non-treated (normal) group $(n=8)$ was used in the experiment. Evaluation of the antinephritic effect of test drugs was done by comparing biochemical parameters such as urinary protein, plasma cholesterol and urea nitrogen contents and histopathological parameters in the glomeruli of the test drugtreated group with those of the control group.

Urine and blood collections: The $24 \mathrm{hr}$ urine samples were obtained by keeping each animal in an individual metabolic cage for 24 hr at various intervals after the induction of nephritis. At the beginning of the urine collection, each animal received $8 \mathrm{ml}$ of distilled water orally without feeding. The urine was then centrifuged at $3,000 \mathrm{rpm}$ for $15 \mathrm{~min}$ at $4^{\circ} \mathrm{C}$, and the supernatant was used for the determination of protein. Blood samples were also obtained at various intervals after the induction of nephritis. In this case, each 0.4 $\mathrm{ml}$ of blood was drawn from the tail vein of 
conscious animals with a disposable microsyringe and put into a tube containing 4.5 umol of EDTA.2Na. The blood was centrifuged at $5.000 \mathrm{rpm}$ at $4^{\circ} \mathrm{C}$ to obtain the plasma for the determination of cholesterol, urea nitrogen and antibody titer against rabbit $r-\mathrm{G}$. Immediately after the last collection of urine samples, blood was also taken from the renal vein for the measurement of platelet aggregation.

Measurements of urinary protein, plasma cholesterol (CL), urea nitrogen (UN) content, antibody titer and platelet aggregation: The urinary protein content was determined by the method of Kingsbury et al. (8) and expressed as $\mathrm{mg} / 24 \mathrm{hr}$ urine. The plasma cholesterol and UN contents were determined in accordance with the methods of Cox (9) and Zurkowski (10), respectively. and expressed as $\mathrm{mg} / \mathrm{dl}$ plasma. The plasma anti- body titer against rabbit $\gamma-\mathrm{G}$ was determined by indirect hemagglutination using sensitized sheep red blond cells (11)

Platelet aggregation was measured with a whole blood aggregometer (Chronolog Co., Ltd. . Tokyo) as reported previously (12).

Assessment of histopathological parameters in glomeruli: For light microscopic study, the kidney was fixed in alcohol and then the tissues embedded in paraffin were cut into 2-3 $\mu \mathrm{m}$ thick sections. The sections were stained with hematoxylin and eosin and Masson trichrome. The crescent formation. adhesion to Bowman's capsule of capillary walls (adhesion) and fibrinoid necrosis in glomeruli were observed under a light microscope. For assessing each histopathological parameter, the degrees of crescent formation, adhesion and fibrinoid necrosis were scored as 1 (mild), 2 (moderate) and 3 (severe): crescent formation

a

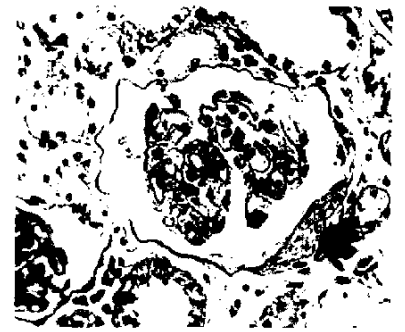

$\mathrm{b}$

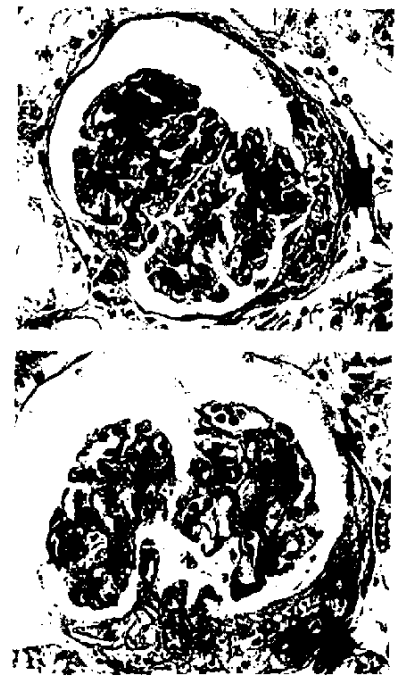

adhesion
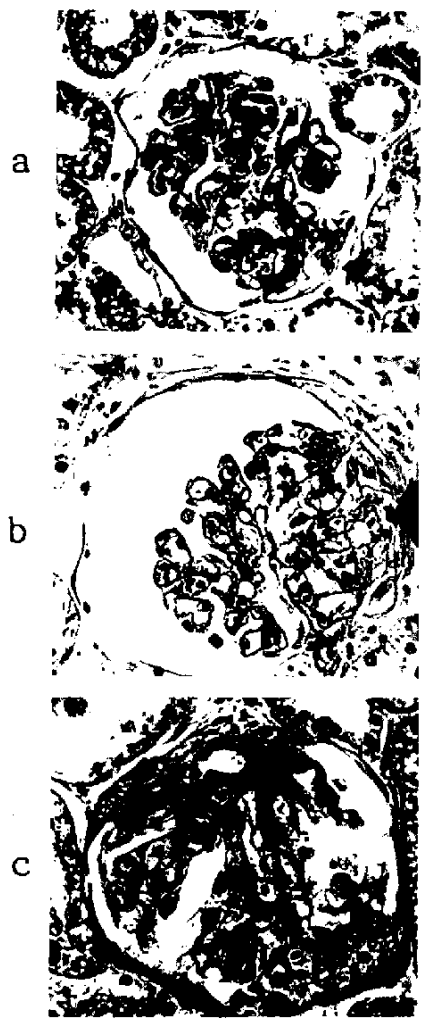

fibrinoid necrosis
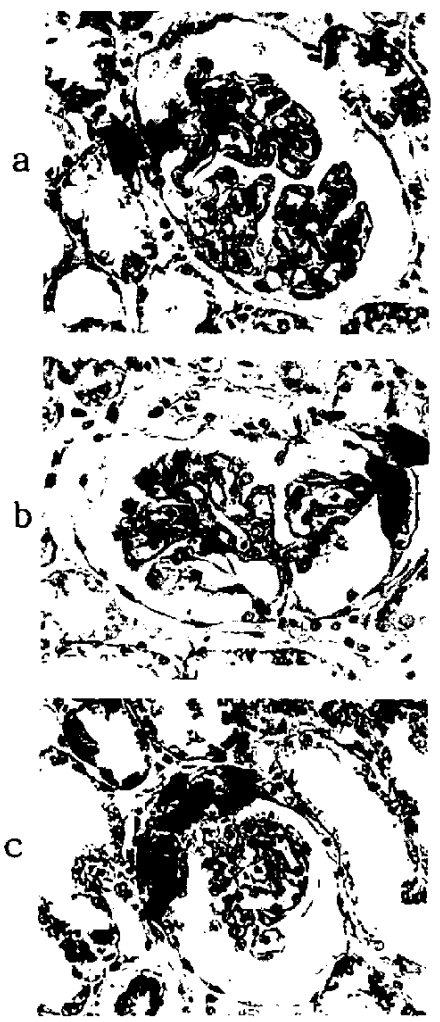

Fig. 1. Typical micrographs of crescent formation, the adhesion of capillary walls to Bowmari's capsule (adhesion) and fibrinoid necrosis in glomeruli. The degree of changes in each parameter (a: mild, b: moderate, c: severe) 
Typical examples of the degrees of necrosis are shown in Fig. 1. The number of glomeruli corresponding to each score was represented as $n_{1}, n_{2}$ and $n_{3}$. The crescent formation index (Cl), the adhesion index (Al) and the fibrinoid necrosis index $(\mathrm{FI})$ were calculated by the following formula: $\mathrm{Cl}, \mathrm{Al}$ and $\mathrm{FI}=1 \times \mathrm{n}_{1}+2 \times \mathrm{n}_{2}$ $+3 \times n_{3}$. Moreover, the index of glomerular lesions (IGL) was calculated to evaluate the degree of glomerular lesions synthetically as follows:

$$
I G L=\frac{(3 \times \mathrm{CI})+(2 \times \mathrm{Al})+(1 \times \mathrm{FI})}{(3+2+1) \times 50}
$$

All the above experiments were performed "blindly" on coded sections.

Statistical analysis: The data represent the mean \pm S.D., and the results were statistically evaluated by analysis of variance. Student's $t$-test and Mann-Whitney's $U$-test.

\section{Results}

1. Effects of TJ-8014 and dipyridamole administered from the heterologous phase on crescentic-type anti-GBM nephritis in rats

Urinary protein excretion (Fig. 2): When test drugs were given from the day after the
anti-GBM serum injection (the 1st day) to the 39 th day, TJ-8014 at $2.0 \mathrm{~g} / \mathrm{kg} /$ day, p.o. markedly inhibited the urinary protein excretion from the 20th day onward. Namely, the inhibitions were $52 \%$ (normal, $15 \pm 5 \mathrm{mg} /$ day: control, $349 \pm 181 \mathrm{mg} /$ day; $2.0 \mathrm{~g} / \mathrm{kg} /$ day. p.o., $176 \pm 91 \mathrm{mg} / \mathrm{day}$ ) and $60 \%$ (normal, $16 \pm$ $3 \mathrm{mg} /$ day; control, $232 \pm 99 \mathrm{mg} /$ day: $2.0 \mathrm{mg} /$ day. p.o., $84 \pm 72 \mathrm{mg} /$ day). respectively, on the 30th and 39th days. However, TJ-8014 at low doses ( 0.1 and $0.5 \mathrm{~g} / \mathrm{kg} /$ day. p.o.) and dipyridamole $(0.4 \mathrm{~g} / \mathrm{kg} /$ day, p.o.) showed no significant inhibition throughout the experimental period.

Plasma CL and UN contents (data not shown): On the 40th day. TJ-8014 at $2.0 \mathrm{~g} /$ $\mathrm{kg} /$ day, p.o., inhibited the elevation of the plasma CL level by $55 \%$ (normal, $64 \pm 10 \mathrm{mg} /$ dl; control, $228 \pm 43 \mathrm{mg} / \mathrm{dl} ; 2.0 \mathrm{~g} / \mathrm{kg} / \mathrm{day}$, p.o. $128 \pm 44 \mathrm{mg} / \mathrm{dl})$. TJ -8014 at a low dose $(0.5$ $\mathrm{g} / \mathrm{kg} / \mathrm{day}$, p.o.) and dipyridamole $(0.4 \mathrm{~g} / \mathrm{kg} /$ day, p.o.) showed only a tendency to inhibit the elevation. On the other hand, the elevation of plasma UN level was significantly inhibited only by $2.0 \mathrm{~g} / \mathrm{kg} /$ day, p.o., of TJ -8014 on the 29 th day (normal, $11.4 \pm 1.3 \mathrm{mg} / \mathrm{dl}$; control, $18.0 \pm 1.9 \mathrm{mg} / \mathrm{dl} ; 2.0 \mathrm{~g} / \mathrm{kg} /$ day, p.o., $14.2 \pm$

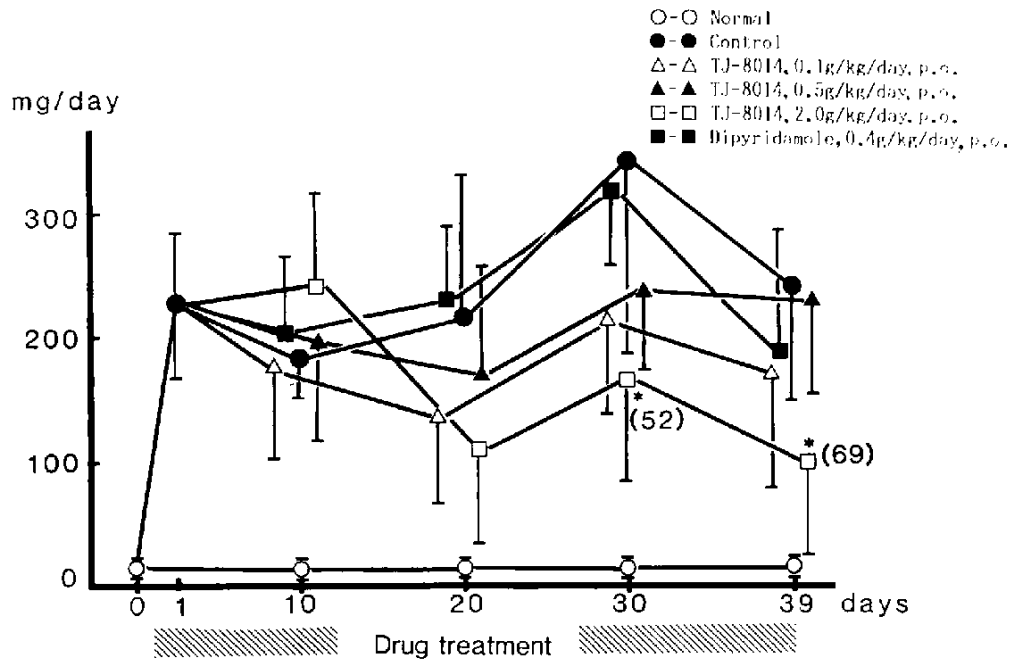

Fig. 2. Effects of $\mathrm{TJ}-8014$ and dipyridamole administered from the heterologous phase on urinary protein excretion in crescentic type anti-GBM nephritis in rats. Each plot denotes the mean $\pm S . D$. of 8 rats. The number in parentheses indicates a percent inhibition which is derived from the following formula:

$\frac{C-T}{C-N} \times 100$ (C: Control. T: Test drug. N: Normal)

* indicates a significant difference from the control at $P<0.05$. 


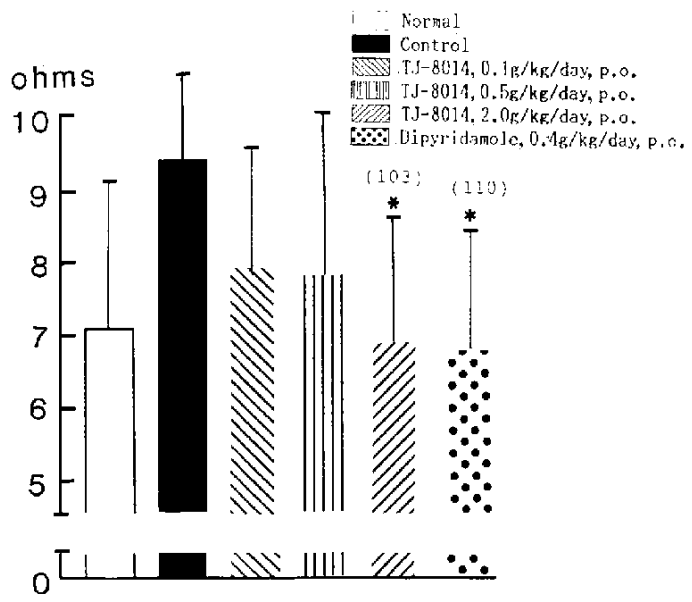

Fig. 3. Effects of $T J-8014$ and dipyridamoie administered from the heterologous phase on platelet aggregation in crescentic-type anti-GBM nephritis in rats. Each column denotes the mean \pm S.D. of 5 rats. The number in parentheses indicates a percent inhibition which is derived from the following formula:

$$
\frac{\mathrm{C}-\mathrm{T}}{\mathrm{C}-\mathrm{N}} \times 100 \text { (C: Control, T: Test drug, N: Normal). }
$$

* indicates a significant difference from the control at $P<0.05$.
$1.8 \mathrm{mg} / \mathrm{dl})(\mathrm{P}<0.05)$

Plasma antibody titer against rabbit $\gamma-\mathrm{G}$ (data not shown) and platelet aggregation (Fig. 3): The plasma antibody titer against rabbit $\gamma-G$ and platelet aggregation were determined on the 40th day. In this case, the elevation of the antibody titer was not inhibited by anyidoses of TJ-8014 and dipyridamole (Control, $9.5 \pm 2.5$ titer: $0.1 \mathrm{~g} / \mathrm{kg} \mathrm{TJ}$, $8.4 \pm 3.2$ titer: $0.5 \mathrm{~g} / \mathrm{kg}$ TJ, $9.4 \pm 1.1$ titer; 2.0 $\mathrm{g} / \mathrm{kg} \mathrm{TJ}, 8.9 \pm 1.3$ titer; Dipyridamole, $9.4 \pm 2.1$ titer).

On the other hand, the elevation of the platelet aggregation was significantly inhibited by TJ -8014 at $2.0 \mathrm{~g} / \mathrm{kg} / \mathrm{day}$, p.o., and dipyridamole $(0.4 \mathrm{~g} / \mathrm{kg} / \mathrm{day}, \mathrm{p} . \mathrm{o}$.) by almost normal level (normal, $7.2 \pm 0.6$ ohms; control, $9.5 \pm 2.3$ ohms: $2.0 \mathrm{~g} / \mathrm{kg} /$ day TJ-8014, p.o.. $6.7 \pm 0.6 \mathrm{ohms}$; dipyridamole, $6.6 \pm 1.1 \mathrm{ohms}$ ). Treatment with the low doses of TJ-8014 10.1 and $0.5 \mathrm{~g} / \mathrm{kg} /$ day, p.o.) only tended to inhibit the elevation.

Histopathological parameters in glomeruli (Fig. 4): At the histopathological observation of the glomeruli on the 40th day, $\mathrm{TJ}-8014$ at
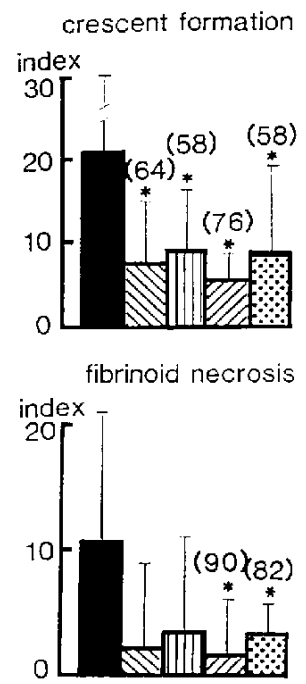

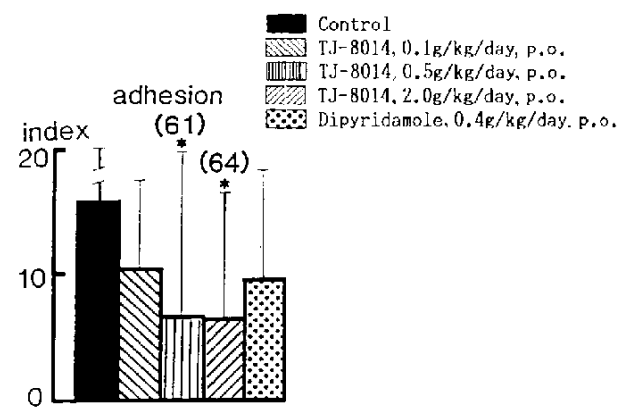

index of glomerular lesions

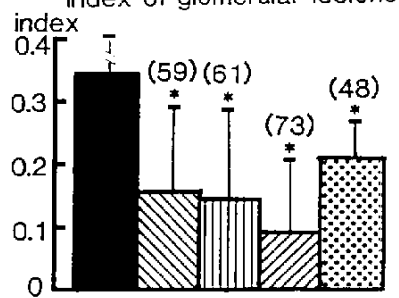

Fig. 4. Effects of TJ-8014 and dipyridamole administered from the heterologous phase on histopathological parameters in glomerulı in crescentic-type anti-GBM nephritis in rats. Each column denotes the mean \pm S. D. of 8 rats. The number in parentheses indicates a percent inhibition which is derived from the following formula:

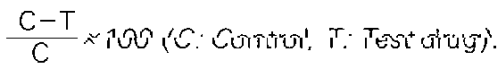

- indicates a significant difference from the control at $P<0.05$. 
$2.0 \mathrm{~g} / \mathrm{kg} /$ day, p.o., markedly reduced the $\mathrm{Cl}$. the $\mathrm{Al}$ and the $\mathrm{Fl}$ by $76 \%, 64 \%$ and $90 \%$. respectively. In addition, it significantly reduced the $\mathrm{Cl}$ and the $\mathrm{Al}$ at $0.5 \mathrm{~g} / \mathrm{kg} /$ day, p.o., and only the $\mathrm{Cl}$ at $0.1 \mathrm{~g} / \mathrm{kg} /$ day, p.o. Dipyridamole $(0.4 \mathrm{~g} / \mathrm{kg} /$ day, p.o.) also significantly reduced the $\mathrm{Cl}$ and $\mathrm{Fl}$ by $58 \%$ and $82 \%$, respectively. When the degree of glomerular lesions was synthetically evaluated as IGL, TJ-8014 (2.0 g/ $/ \mathrm{kg} /$ day, p.o.) and dipyridamole $(0.4 \mathrm{~g} / \mathrm{kg} /$ day, p.o.) reduced the index by $73 \%$ and $48 \%$, respectively. Representative micrographs of glomeruli from drug-treated and control rats are given in Fig.
5

2. Effects of TJ-8014 and dipyridamole administered from the autologous phase on cresecentic-type anti-GBM nephritis in rats

Urinary protein excretion (Fig. 6): When test drugs were given from the 22 nd day to the 53rd day, TJ-8014 showed only a tendency to inhibit the protein excretion.

Plasma $\mathrm{CL}, \mathrm{UN}$ and platelet aggregation (data not shown): $\mathrm{TJ}-8014$ given at $5.0 \mathrm{~g} / \mathrm{kg} /$ day, p.o.. significantly reduced the elevated plasma UN level through the 28th day to the 53 rd day (the 28th day: Normal, $17.8 \pm 2.8$ $\mathrm{mg} / \mathrm{dl}$ : Control. $28.3 \pm 8.7 \mathrm{mg} / \mathrm{dl}$; $5.0 \mathrm{~g} / \mathrm{kg}$
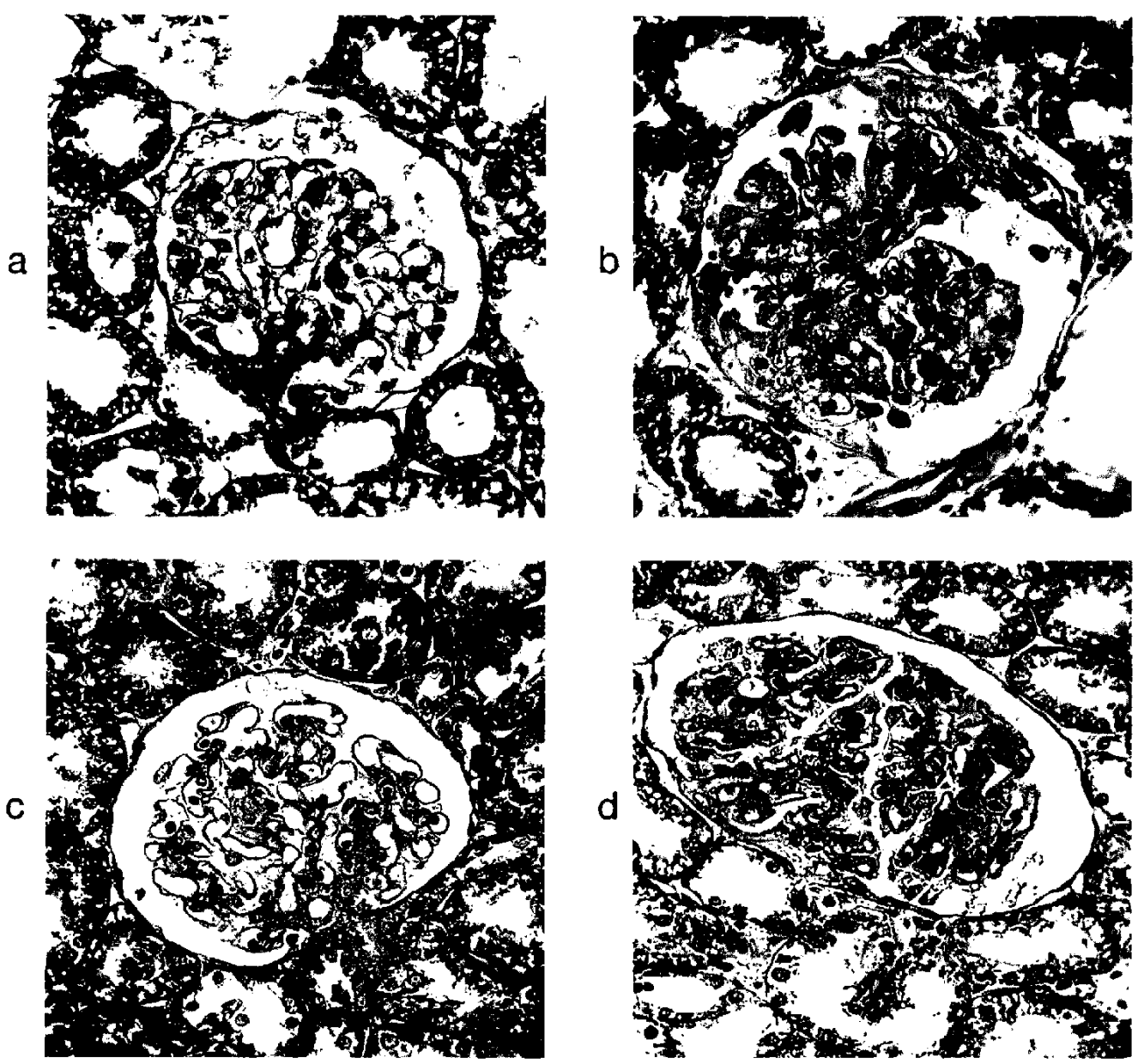

Fig. 5. Light micrographs of glomeruli from rats of the normal group (a): control group (b): group given TJ-8014, $2.0 \mathrm{~g} / \mathrm{kg} / \mathrm{dav}$, p.o. (c); group given dipyridamole, $0.4 \mathrm{~g} / \mathrm{kg} /$ day, p.o. (d). The drug-treated rats were examined on the 40th day after i.v. injection of anti-GBM serum (Masson's trichrome stain $\times 400$ ). Note that crescent formation is markedly less in the group treated with $\mathrm{TJ}-8014$ than in the control. 


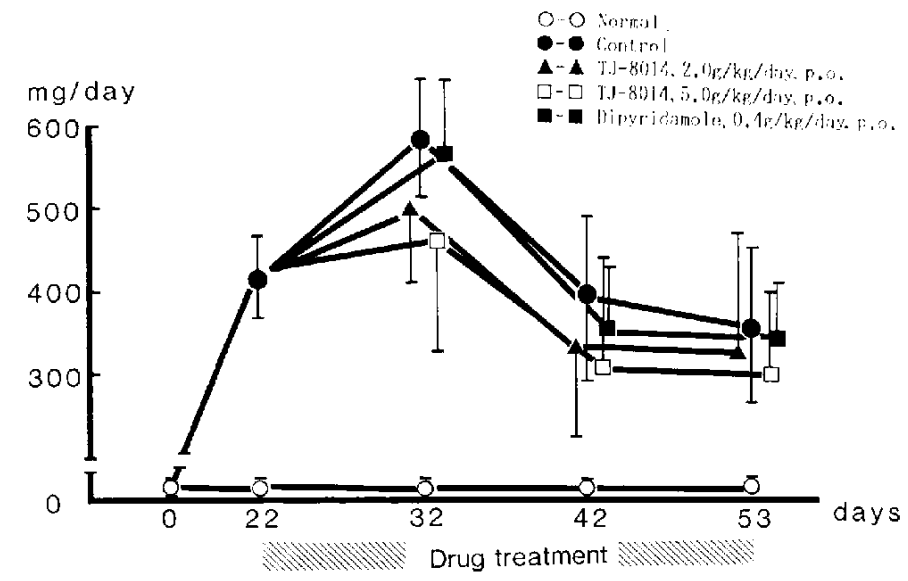

Fig. 6. Effects of TJ-8014 and dipyridamole administered from the autologous phase on urinary protein excretion. Each column denotes the mean \pm S.D. of 8 rats.
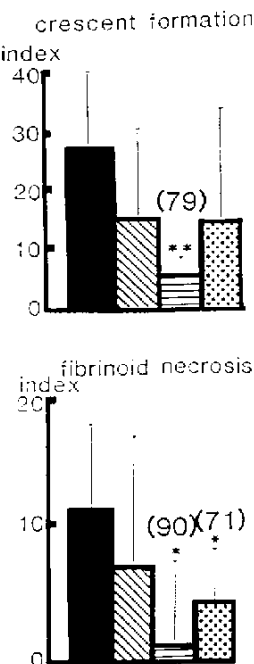

Control

T.J-8014, 2.0g/kp/day, p.o.

$\Rightarrow$ TJ-8014, 5. $\mathrm{De}_{2} / \mathrm{kg} / \mathrm{day}, \mathrm{p.o}$

adheisen Dipyridamole, $0.4 \mathrm{k} / \mathrm{kg} / \mathrm{day}, \mathrm{p.o}$.

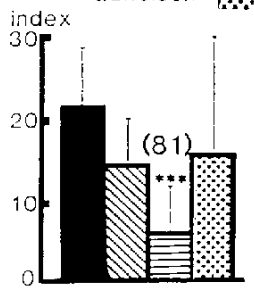

incex of glomerular lesions

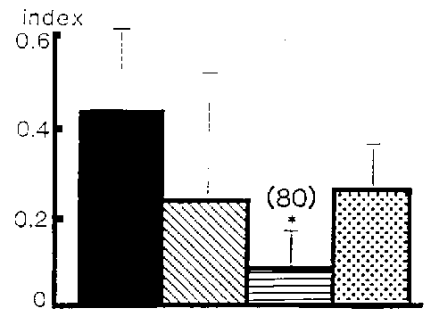

Fig. 7. Effects of TJ-8014 and dipyridamole administered from the autologous phase on histopathological parameters in glomeruli in crescentic-type anti-GBM nephritis in rats. Each column denotes the mean \pm S.D. of 8 rats. The number in parentheses indicates a percent inhibition which is derived from the following formula:

$\frac{\mathrm{C}-\mathrm{T}}{\mathrm{C}}-\times 100$ (C: Control, T: Test drug).

${ }^{*},{ }^{*}$ and $* *$ indicate a significant difference from the control at $P<0.05,0.01$ and 0.001 , respectively.

TJ, $19.0=1.6 \mathrm{mg} / \mathrm{dl} ; \quad P<0.05$ vs. Control), although at this dose, it could not reduce the elevated plasma $\mathrm{CL}$ level. When the platelet aggregation was measured on the 53rd day, the platelet aggregation of the control had already been restored to the normal !evel. No difference was observed in the platelet aggragation between the control and test drugs.

Histopathological parameters in glomeruli (Fig. 7): When histopathological assessment in glomeruli was performed on the 53 rd day. TJ-8014 at $5.0 \mathrm{~g} / \mathrm{kg} /$ day p.o. markedly re- 
duced the $\mathrm{Cl}$, the $\mathrm{Al}$ and the $\mathrm{FI}$ by $79 \%, 81 \%$ and $90 \%$, respectively. Dipyridamole $(0.4 \mathrm{~g} /$ $\mathrm{kg} / \mathrm{day}$, p.o.) significantly reduced the only the $\mathrm{FI}$ by $71 \%$. The IGL was significantly reduced by $80 \%$ only by $5.0 \mathrm{~g} / \mathrm{kg} /$ day of $T \mathrm{~J}$ 8014, p.o.

\section{Discussion}

The glomerular injury of the anti-GBM nephritis in rats may be initiated by immunological reactions during the following two phases: Immediately after the injection of rabbit anti-GBM serum, the immunological reaction in the heterologous phase is caused by immediate fixation of the injected antiGBM antibody to the glomeruli. Consecutively, 7 to 10 days later, the reaction in the autologous phase is caused by binding of host antibody against the injected rabbit antiGBM serum protein to the anti-GBM antibody already fixed to the glomeruli. Our previous study indicated that immunization with rabbit $\gamma-G$ following i.v. injection of rabbit antiGBM serum to rats caused severe glomerular injury. which led to extensive formation of crescents by enhancing the immune response in the autologous phase via the persistent formation of the host antibody against rabbit $r-G(6)$.

In the present experiment, the antinephritic effect of TJ-8014, a new Japanese herbal medicine, on crescentic-type anti-GBM nephritis in rats was evaluated by starting the administration from the heterologous phase (from the day after the anti-GBM serum injection). As a result, TJ -8014 at $2.0 \mathrm{~g} / \mathrm{kg} /$ day, p.o.. markedly inhibited the urinary protein excretion and the elevation of serum cholesterol level as well as glomerular histopathological changes such as crescent formation, adhesion and fibrinoid necrosis on the 39 th or 40 th day. TJ -8014 at low doses $(0.1$ and $0.5 \mathrm{~g} / \mathrm{kg} /$ day, p.o.) and dipyridamole $(0.4 \mathrm{~g} / \mathrm{kg} / \mathrm{day}$, p.o.) inhibited only histopathological changes. When the administration of test drugs was started from the autologous phase (from the 22 nd day after the anti-GBM serum injection). TJ-8014 at $2.0 \mathrm{~g} / \mathrm{kg}$, p.o., and dipyridamole at $0.4 \mathrm{~g} / \mathrm{kg} / \mathrm{day}$, p.o., showed no apparent effect by the 53rd day. However, TJ-8014 administered at $5.0 \mathrm{~g} / \mathrm{kg} /$ day, p.o., markedly inhibited the elevation of plasma UN and histopathological changes, although the dose had only a tendency to inhibit the urinary protein excretion. Thus, TJ8014 showed a more marked effect than dipyridamole on the crescentic-type nephritis. In addition, the established nephritis, which had already developed to massive proteinuria and hvpercholesterolemia, was improved only by the high dose of $5.0 \mathrm{~g} / \mathrm{kg}$ of TJ-8014, p.o.

The details of the mechanisms by which TJ-8014 was effective on the crescentic-type nephritis remain unclear. We previously reported that mizoribine, an immunosuppressive agent, inhibited the elevation of the serum antibody titer against rabbit $\gamma-G$ and was markedly effective on this nephritis (13). However, the serum antibody titer was little affected by TJ-8014.

Generally speaking, intraglomerular coagulation and platelet aggregation are thought to play an important role in the development and progression of various renal diseases (14-18). It ts well-known that the crescent formation, a main histopathological characteristic of the nephritic model used in the experiment, is closely related to intraglomerular formation of platelet thrombosis and reflects intraglomerular coagulation (19). Immunization with rabbit $\gamma-G$ in this nephritic model may cause platelet thrombosis as a result of intraglomerular hypercoagulation and platelet hyperaggregation subsequent to the persistent immune responses in the autologous phase. We reported that the platelet aggregation in the crescentictype model markedly elevated from the 5th day after the anti-GBM serum injection and was maintained at higher levels than normal levels through a 40 day-observation period (20). In addition. the elevation of the aggregation was significantly higher in the crescentic-type model than in the originaltype model. In the present study. TJ-8014 $(2.0 \mathrm{~g} / \mathrm{kg} /$ day. p.o.) and dipyridamole $(0.4 \mathrm{~g} /$ $\mathrm{kg} /$ day, p.o.) administered from the heterologous phase inhibited the elevation of the platelet aggregation by almost normal level when it was determined on the 40th day. This result strongly suggests that when administered from the heterologous phase. TJ-8014. like dipyridamole, may prevent glomerular histopathological changes by the antiplatelet 
action of both drugs. In addition, the antiplatelet action of both drugs may participate in the prevention of the urinary protein excretion. However, treatment with both drugs at the doses required to show antiplatelet action from the autologous phase failed to improve the established nephritis. TJ-8014 at the high dose of $5.0 \mathrm{~g} / \mathrm{kg} /$ day, p.o., was effective even by the administration from the autologous phase. Therefore, the effect of TJ-8014 given at a high dose from the autologous phase is thought to be due to actions other than the antiplatelet action.

More recently, we found that in the original-type model, the adrenal corticosterone level was markedly decreased during the process of neprititis, and TJ-8014 inhibited the decrease in the endogenous glucocorticoid (21). Moreover, we demonstrated in the same report that $\mathrm{TJ}-8014$ increased the serum corticosterone level of normal rats. Therefore the antinephritic action of TJ-8014, especialIy at the high dose. may be partly due to the enhanced release of corticosterone from the adrenal cortex.

\section{References}

1 Hattori, T., Nagamatsu, T. and Suzuki, $Y$.: Studies on antinephritic effects of Japanese Kampo medicines in rats (1). Effects of Sairei-to on anti-GBM antibody nephritis in rats. J. Med. Pharm. Soc. Wakan-Yaku 5, 27-33 (1988) (Abs. in English)

2 Hattori, T., Nagamatsu, T. and Suzuki, Y.: Studies on antinephritic effects of Japanese Kampo medicines in rats (2). Effects of Syosaiko-to on anti-GBM antibody neptritis in rats. J. Med. Pharm. Soc. Wakan-Yaku 5, 27-33 (1988) (Abs. in English)

3 Abe, H., Orita, M., Konishi, H. and Arich, S. Effects of Sairei-to on aminonucleoside nephrosis in the rats. J. Med. Pharm. Soc. Nakan-Yak 3 , 24-30 (1986) (Abs. in English)

4 Hattori, T., Nagamatsu, T., Ito, M. and Suzuki, Y.: Studies on antinephritic effect of TJ-8014, a new Japanese Herbal Medicines, and its mechanisms (1): Effect on original-type anti-GBM nephritis in rats and platelet aggregation. Japan. J. Pharmacol. 50, 477-485 (1989)

5 Suzuki, Y., Ogawa, Y., Ito, M. and Nagamatsu, T.: The pharmacological studies on experimental nephritis (8). Histopathological studies on kidney in modified Masugi nephritic rats and antinephritic effect of steroid agent. Phar- macometric 19, 247-257 (1980)

6 Ito, M:, Yamada, H., Okamoto, Y. and Suzuki, Y.: Crescentic type nephritis induced by antiglomerular basement membrane (GBM) serum in rats. Japan. J. Pharmacol. 33, 1145-1154 (1983)

7 Suzuki, Y. and Ito, M.: Studies on antinephritic action of dipyridamole (1). The effect of dipyridamole on anti-GBM antibody induced nephritis in rats. Japan. J. Nephrol. 23, 323-331 (1981) (Abs. in English)

8 Kingsbury, F.B., Clark, C.P., Williams, G. and Post, A.L.: The rapid determination of albumin in urine. J. Lab. Clin. Med. 11, 981-989 (1926)

9 Searcy, R.L. and Cox., F.M.: A modified technique for ultramicro estimation of urea nitrogen. Clin. Chem. Acta 8, 810-812 (1963)

10 Zurkowski, P.: A rapid method for cholesterol determination with a single reagent. Clin. Chem. 10, 451-453 (1964)

11 Mcleish, K.R., Clark, C.P., Williams, G. and Post, A.L.: Suppression of antibody synthesis by prostaglandin $E$ as a mechanism for preventing murine immune complex glomerulonephritis. Lab. Invest. 47, 147-152 (1982)

12 Nagamatsu, T. and Suzuki, Y.: Experimental immune complex glomerulonephritis and platelet aggregability in whole blood. Japan. J. Infiammation 6, 367-371 (1986) (Abs. in English)

13 Okamoto, K., Ito, M. and Suzuki, Y.: Studies on antinephritic effect of mizoribine a new immunosuppressive agent, and azathioprine (2). Effect of crescentic type anti-GBM nephritis in rats. Japan. J. Pharmacol. 34, 33-41 (1984)

14 Vassali, P. and McCluskey, R.T.: The pathogenetic role of the coagulation process in rabbit Masugi nephritis. Am. J. Pathol. 45, 653-677 (1964)

15 Humair, L., Potter, E.V. and Kwaan, H.C.: The role of fibrinogen in renal disease. 1. Production of experimental lesions in mice. J. Lab. Clin. Med. $74,60-7 ?(1969)$

16 Ito, M., Nagamatsu, T. and Suzuki, Y.: Pharmacological studies on experimental nephritic rats (10). Changes in coagulation-fibrinolysis in the course of anti-GBM induced nephritis. Japan. J. Nephrol. 23, 297-308 (1981) (Abs. in English)

17 Parbtani, A. and Cameron, J.S.: Platelet and plasma serotonin concentration in glomerulonephritis !. Thromb. Res. 15, 109-125 (1979)

18 Parbtani, A. and Cameron, J.S.: Platelet and plasma serotorin concentration in glomerulonephritis 11. Cin. Nephrol. 14, 112-123 (1980)

19 Fujimoto, T.: Pathology of Masugi nephritis. 
Forty year's progress and present status. In Masugi Nephritis and Its Immunopathologic Implications, Edited by Okabayashi. A. and Kondo, Y., p. 1-35. Igaku-Shoin. Tokyo and New York (1980)

20 Nagamatsu, T., Tsukushi, $Y$., Ito, M., Kondo, N. and Suzuki, Y.: Antinephritic effect of OKY-046. a thromboxane A synthesis inhibitor (1). Effect on crescentic-type anti-GBM nephritis in rats. Japan. J. Pharmacol. 49, 501-509 (1989)

21 Hattori, H., Nagamatsu, T., Ito, M. and Suzuki, Y.: Studies on antinephritic effect of TJ-8014, a new Japanese herbal medicine, and its mechanisms (2): Effects on the release of corticosterone from adrenal glands. Japan. J. Pharmacol. 51, 117124 (1989) 